\title{
The Anti-Campylobacter Activity and Mechanisms of Pinocembrin Action
}

\author{
Anja Klančnik ${ }^{1, *(\mathbb{D} \text {, Katarina Šimunović }}{ }^{1}$, Jasna Kovac ${ }^{1,2}$, Orhan Sahin ${ }^{3}$, Zuowei Wu ${ }^{3}$, \\ Darinka Vučković ${ }^{4}$, Maja Abram ${ }^{4}$, Qijing Zhang ${ }^{3}$ and Sonja Smole Možina ${ }^{1}$ \\ 1 Department of Food Science and Technology, Biotechnical Faculty, University of Ljubljana, Jamnikarjeva 101, \\ SI-1000 Ljubljana, Slovenia; Katarina.simunovic@bf.uni-lj.si (K.Š.); jasna.kovac@psu.edu (J.K.); \\ Sonja.smole@bf.uni-lj.si (S.S.M.) \\ 2 Department of Food Science, The Pennsylvania State University, University Park, PA 16802, USA \\ 3 Department of Veterinary Microbiology and Preventive Medicine, College of Veterinary Medicine, \\ Iowa State University, Ames, IA 50011, USA; osahin@iastate.edu (O.S.); wuzw@iastate.edu (Z.W.); \\ zhang123@iastate.edu (Q.Z.) \\ 4 Department of Microbiology, Faculty of Medicine, University of Rijeka, Braće Branchetta 20, 51000 Rijeka, \\ Croatia; darinka.vuckovic@medri.uniri.hr (D.V.); maja.abram@medri.uniri.hr (M.A.) \\ * Correspondence: anja.klancnik@bf.uni-lj.si; Tel.: +386-1-320-3762
}

Received: 17 November 2019; Accepted: 7 December 2019; Published: 10 December 2019

\begin{abstract}
We investigated the anti-Campylobacter activity of pinocembrin and its mechanism of action, as well as Campylobacter responses to pinocembrin treatment at the genetic and phenotypic levels, using C. jejuni NCTC 11168 and a multidrug efflux system repressor mutant (11168 $\Delta \mathrm{cmeR})$. At its minimal inhibitory concentration, pinocembrin significantly increased cell membrane permeability of Campylobacter. Interestingly, at sub-inhibitory concentrations, pinocembrin did not significantly alter membrane functionality and it increased bacterial fitness. Treatment with pinocembrin evoked decreased expression of ribosomal proteins and down-regulation of several NADH dehydrogenase I chain subunits and proteins involved in iron uptake. This suggests altered protein production and redox cycle and iron metabolism. Interestingly, the chelation of Fe ions during the treatment with pinocembrin increased $C$. jejuni survival, although there was no increase in the formation of reactive oxygen species. Pre-treatment of $C$. jejuni with sub-inhibitory concentrations of pinocembrin for $2 \mathrm{~h}$ resulted in a $1 \log$ decrease in $C$. jejuni colony forming units in mice liver at 8 days post-infection, compared to untreated $C$. jejuni. These findings suggest that pinocembrin modulates the metabolic activity of $C$. jejuni and that pre-treatment of $C$. jejuni with pinocembrin influences its virulence potential in mice. This anti-Campylobacter potential of pinocembrin warrants further investigation.
\end{abstract}

Keywords: Campylobacter jejuni; pinocembrin; mechanism of antibacterial activity; gene expression; virulence

\section{Introduction}

Campylobacteriosis was the most frequently reported zoonotic disease in humans in Europe over last decade [1]. Diarrhoeal disease and chronic complications of Campylobacter infection are common, including reactive arthritis and Guillain-Barré syndrome [2].

The European Centre for Disease Control has reported increased frequencies of antibiotic-resistant pathogenic bacteria and it is actively encouraging alternative strategies to control Campylobacter contamination and to combat infections without further increases in bacterial resistance [3]. Reduction of Campylobacter jejuni prevalence would decrease the risk of human exposure, which would have substantial positive impact on food safety and public health. Alternative approaches for prevention of Campylobacter contamination have been focused on the use of antimicrobials of natural origins. One 
such product is the 5,7-dihydroxyflavanone, pinocembrin, which is a major flavonoid that is used as a multifunctional active compound in the pharmaceutical industry [4-6]. Pinocembrin is found in a wide range of different plant species and is considered to be part of a normal healthy diet. It is commonly found in honey, propolis, and ginger roots [7]. Pinocembrin has a number of known pharmacological activities, including antibacterial activity [5,6]. However, its potential to inhibit Campylobacter has not been tested to date.

Resistance of $C$. jejuni to antimicrobials, including phenolic compounds and plant extracts, involves the activity of the main resistance-nodulation-cell-division (RND)-type efflux pump, known as CmeABC [8,9]. This efflux system is regulated through the transcriptional repressor CmeR, which is encoded by a gene that is positioned immediately upstream of $c m e A$ and interacts directly with the promoter region of $c m e A B C$, to modulate its expression [10]. Recently, Yang et al. [11] and Zhang et al. [12] defined the impact of substitutions, insertions, and deletions in the cmeR-cmeA intergenic region of C. jejuni and reported that strains with specific polymorphisms are more likely to show increased resistance to tetracycline, doxycycline, florfenicol, chloramphenicol and gentamicin [12,13]. This is due to decreased binding of $\mathrm{CmeR}$ to $\mathrm{CmeABC}$, which results in overexpression of the efflux pump.

The aim of this study was to investigate the mechanisms of pinocembrin action in resistant Camplyobacter using a C. jejuni NCTC 11168 construct with an inactivated efflux system repressor $(11168 \Delta c m e R)$ as a model strain with induced antimicrobial resistance. The effects of pinocembrin on growth kinetics, membrane integrity, oxidative stress induction, and global gene transcription were investigated in vitro. Finally, the potential virulence-modifying effects of $C$. jejuni pre-treatment with sub-inhibitory concentrations of pinocembrin were investigated in vivo through quantification of the bacterial burden in the liver of infected BALB/c mice.

\section{Materials and Methods}

\subsection{Bacterial Strains and Growth Conditions}

The minimal inhibitory concentrations (MICs) were determined for the reference strain C. jejuni NCTC 11168 (National Collection of Type Cultures) and for C. jejuni NCTC $11168 \Delta c m e R$, which has a disrupted open reading frame of the gene encoding for the efflux repressor $c m e R$, and thus provides a model strain of intrinsic resistance [10]. Additionally, two C. jejuni NCTC 11168 mutants with disrupted $c m e B$ and $c m e F$ genes were also included in the study [9]. Cultures were stored at $-80^{\circ} \mathrm{C}$, and grown on Mueller-Hinton agar (Oxoid, Hampshire, UK) with incubations at $42{ }^{\circ} \mathrm{C}$ under microaerobic conditions $\left(5 \% \mathrm{O}_{2}, 10 \% \mathrm{CO}_{2}\right.$, in $\left.85 \% \mathrm{~N}_{2}\right)$ for $24 \mathrm{~h}$. The second passage of each culture in exponential growth phase was used in the experiments.

\subsection{Antimicrobial Susceptibility Testing and Resistance Mechanism}

The microdilution method was used to measure the MICs, with optical density measurements at $600 \mathrm{~nm}\left(\mathrm{OD}_{600}\right)$ and addition of a bacterial viability indicator (BacTiter-Glo reagent; Promega Corporation, Madison, WI, USA) [14]. The MIC was the lowest concentration where no metabolic activity was observed after $24 \mathrm{~h}$, on the basis of absence of a bioluminescence signal, measured using a microplate reader (Tecan, Mannedorf/Zurich, Switzerland) [14]. Stock solutions of pinocembrin were prepared in dimethyl sulphoxide (DMSO; Sigma-Aldrich, St. Louis, MO, USA). The antimicrobial activity of pinocembrin was tested against $C$. jejuni NCTC 11168 and its efflux pump knockout mutant strains that lack functional genes for the efflux pumps CmeABC $(\triangle c m e B)$ and $\mathrm{CmeDEF}(\Delta c m e F)$ and for the efflux pump repressor $\mathrm{CmeR}(\Delta c m e R)$. Additionally, the antimicrobial activity of pinocembrin was tested using disc diffusion and agar-well diffusion according to EUCAST 2019 [15]. The contents of the compounds per disc ( $7 \mathrm{~mm}$ diameter) and well ( $4 \mathrm{~mm}$ diameter) were as follows: ciprofloxacin $5 \mu \mathrm{g}$, erythromycin $15 \mu \mathrm{g}$, and pinocembrin of $100 \mu \mathrm{g}, 50 \mu \mathrm{g}, 25 \mu \mathrm{g}$, and $12.5 \mu \mathrm{g}$. Ciprofloxacin and erythromycin (Sigma-Aldrich, St. Louis, MO, USA) were used for comparisons of the antimicrobial effects. All of the MIC measurements were carried out in triplicate with appropriate controls. 


\subsection{Time-Kill Kinetics}

The time-kill kinetics were determined for C. jejuni NCTC $11168 \triangle c m e R$ using the broth microdilution method, with incubation at $42{ }^{\circ} \mathrm{C}$ under microaerobic conditions, as described previously [16]. Sequential plating of serial culture dilutions was carried out on Mueller-Hinton agar, at $0 \mathrm{~h}, 3 \mathrm{~h}, 6 \mathrm{~h}$, and $24 \mathrm{~h}$ after addition of pinocembrin at $16 \mu \mathrm{g} / \mathrm{mL}(0.25 \times \mathrm{MIC}), 32 \mu \mathrm{g} / \mathrm{mL}(0.5 \times \mathrm{MIC})$, $64 \mu \mathrm{g} / \mathrm{mL}$ (MIC), and $128 \mu \mathrm{g} / \mathrm{mL}(2 \times$ MIC). The colony forming units (CFUs) were counted after $24 \mathrm{~h}$ incubation at $42{ }^{\circ} \mathrm{C}$ under microaerobic conditions [16].

\subsection{Membrane Integrity}

The influence of pinocembrin on the membrane integrity of $C$. jejuni NCTC $11168 \Delta c m e R$ was investigated at $16 \mu \mathrm{g} / \mathrm{mL}(0.25 \times \mathrm{MIC})$ to $128 \mu \mathrm{g} / \mathrm{mL}(2 \times \mathrm{MIC})$, using Live/Dead BacLight Bacterial Viability kits (L-7012; Molecular Probes, Eugene, OR, USA), as reported previously [17]. Two individual experiments were carried out in duplicate. Membrane disruption (\%) was calculated from the kinetics measurements of the treated relative to the untreated cultures [17].

\subsection{Gene Expression}

The influence of pinocembrin on gene expression in C. jejuni NCTC $11168 \Delta c m e R$ was evaluated using DNA microarray analysis and confirmed using quantitative real-time (qRT)-PCR, as previously described [17]. Overnight log-phase cultures incubated for $16 \mathrm{~h}$ at $42{ }^{\circ} \mathrm{C}$ and under a microaerophilic atmosphere were adjusted to $\mathrm{OD}_{600}$ of 0.2 in Mueller-Hinton broth using a spectrophotometer (Smart Spec; Bio-Rad, Hercules, CA, USA). These cultures were then treated with $16 \mu \mathrm{g} / \mathrm{mL}$ pinocembrin (i.e., $0.25 \times$ MIC). DMSO $(0.048 \%)$ was added as solvent to the untreated samples. These cultures were treated microaerobically for $2 \mathrm{~h}$ at $42{ }^{\circ} \mathrm{C}$, with shaking. The experiments were carried out as three biological replicates. After the treatment, the RNA Protect Bacteria reagent (Qiagen, Maryland, USA) was added to the cultures to prevent mRNA degradation. Total RNA was isolated using RNeasy mini kits (Qiagen), and further treated using Ambion Turbo DNA-free kits (Invitrogen, Carlsbad, CA, USA), for removal of any contaminating DNA.

Quantitative real-time PCR was performed using a RT-PCR detection system (ABI 7500; Applied Biosystems, Thermo Scientific, Waltham, MA, USA) with the universal KAPA SYBR One-Step qRT-PCR kits (Kapa Biosystems, Boston, MA, USA). The qRT-PCR primers (Supplementary Table S1) were designed using the Primer3 online tool. A standard quantification curve was generated for each RNA template using 10-fold serial dilutions from $25 \mathrm{ng} / \mu \mathrm{L}$ to $0.0025 \mathrm{ng} / \mu \mathrm{L}$. Quantitation was performed in $15 \mu \mathrm{L}$ reactions with three technical replicates of three biological replicates, using the following program: $10 \mathrm{~min}$ at $50{ }^{\circ} \mathrm{C} ; 5 \mathrm{~min}$ at $60{ }^{\circ} \mathrm{C} ; 3 \mathrm{~min}$ at $95^{\circ} \mathrm{C}$; and 40 cycles of $10 \mathrm{~s}$ at $95{ }^{\circ} \mathrm{C}$ and $30 \mathrm{~s}$ at $58^{\circ} \mathrm{C}$. The melt curve analysis was performed after the amplification. The $16 \mathrm{~S}$ rRNA gene served as an internal normalization standard for calculation of the relative fold-changes in gene expression, using the comparative threshold cycle method $(\Delta \Delta C \mathrm{t})$ [18].

\subsection{Intracellular Oxidation}

The level of intracellular reactive oxygen species (ROS) as a result of treatments with a sub-inhibitory concentration of pinocembrin of $16 \mu \mathrm{g} / \mathrm{mL}(0.25 \times \mathrm{MIC})$ was measured as described previously [14].

\subsection{Oxidative Stress Reduction by Iron Chelation with 2,2-Dipyridyl}

Campylobacter jejuni $11168 \Delta$ cmeR suspensions $\left(\mathrm{OD}_{600}, 0.2\right)$ were prepared in phosphate-buffered saline and then treated with pinocembrin $(64 \mu \mathrm{g} / \mathrm{mL}), 2,2$-dipyridyl $(78 \mu \mathrm{g} / \mathrm{mL})$ and pinocembrin and 2,2-dipyridyl combined [19]. An untreated Campylobacter culture was used as the control. The cultures were incubated for $24 \mathrm{~h}$ at $42{ }^{\circ} \mathrm{C}$ under microaerobic conditions. The experiment was carried out in triplicate, with sampling at 2, 6, and $24 \mathrm{~h}$. The data are presented as $\log \mathrm{CFU} / \mathrm{mL}$. 


\subsection{Motility Assay on Soft Agar}

For the motility assay, C. jejuni NCTC 11168 and C. jejuni NCTC $11168 \Delta c m e R$ were grown overnight on Mueller-Hinton agar and then re-suspended in phosphate-buffered saline to $\mathrm{OD}_{600} 0.2$. Pinocembrin was added to the Campylobacter cultures at $32 \mu \mathrm{g} / \mathrm{mL}(0.5 \times \mathrm{MIC})$ and an untreated Campylobacter culture was used as the control. These cultures were incubated for $2 \mathrm{~h}$ at $42{ }^{\circ} \mathrm{C}$ under microaerobic conditions. One microliter of the bacterial suspension was stabbed into $0.5 \%$ Mueller-Hinton agar and incubated for $48 \mathrm{~h}$ at $42{ }^{\circ} \mathrm{C}$ under microaerobic conditions. Motility was defined as the diameters of the colonies, with two independent experiments carried out in triplicate.

\subsection{In-Vivo Testing of Campylobacter Virulence Potential}

These experiments used C. jejuni NCTC 11168 and C. jejuni NCTC $11168 \triangle c m e R$ as controls, and the same $C$. jejuni strains pre-treated with $32 \mu \mathrm{g} / \mathrm{mL}(0.5 \times \mathrm{MIC})$ pinocembrin for $2 \mathrm{~h}$ at $42{ }^{\circ} \mathrm{C}$ under microaerobic conditions. The strains were grown overnight on Mueller-Hinton agar and re-suspended in phosphate-buffered saline to $\mathrm{OD}_{600}$ 0.2. In vivo experiments were performed in $\mathrm{BALB} / \mathrm{c}$ mice according to ethical clearance No. 2170-24-01-3-07-02 and as previously described [19].

\subsection{Statistical Analysis}

Statistical analyses were carried out for the antimicrobial assays, intracellular oxidation, oxidative stress reduction by iron chelation, and intracellular energy metabolism by one-way ANOVA using SPSS Statistics 21 (IBM Corp., Armonk, NY, USA). Statistical analysis of the microarray results was carried out in $\mathrm{R}$, using the LIMMA package [20].

\section{Results}

\subsection{Anti-Campylobacter Activity of Pinocembrin, and the Resistance Mechanism}

To evaluate the anti-Campylobacter activity of pinocembrin and the role of active efflux in Campylobacter resistance against pinocembrin, we determined the MICs for the wild-type C. jejuni NCTC 11168 and the three knockout mutants of C. jejuni NCTC 11168, with the defective efflux transporter genes $c m e B$ and $c m e F$ and transcriptional repressor $c m e R$. The antimicrobial activity of pinocembrin was moderate against $C$. jejuni NCTC 11168 and weaker compared to the antibiotics ciprofloxacin (MIC $0.062 \mu \mathrm{g} / \mathrm{mL}$ ) and erythromycin (MIC $0.250 \mu \mathrm{g} / \mathrm{mL}$ ), with a MIC of $64 \mu \mathrm{g} / \mathrm{mL}$. When tested against the efflux pump mutants, the greatest changes in the susceptibility to pinocembrin were seen in the $c m e B$ gene mutant, with decreased MICs for pinocembrin of 4-fold (Table 1). With the cmeF and cmeR mutants, no MIC changes were seen (Table 1, Supplementary Table S2), as compared with the wild-type C. jejuni NCTC 11168.

Table 1. Antimicrobial activities of ciprofloxacin, erythromycin, and pinocembrin against C. jejuni NCTC 11168 and its efflux pump knockout mutant strains that lack functional genes for efflux pumps $\mathrm{CmeABC}(\triangle c m e B)$ and $\mathrm{CmeDEF}(\Delta c m e F)$, and the efflux pump repressor $\mathrm{CmeR}(\Delta c m e R)$, presented as minimal inhibitory concentration (MIC) in $\mu \mathrm{g} / \mathrm{mL}$.

\begin{tabular}{|c|c|c|c|}
\hline \multirow{2}{*}{ Strain } & \multicolumn{3}{|c|}{ MIC ( $\mu \mathrm{g} / \mathrm{mL})$} \\
\hline & Ciprofloxacin & Erythromycin & Pinocembrin \\
\hline C. jejuni NCTC 11168 & 0.062 & 0.25 & 64 \\
\hline $\begin{array}{c}\text { C. jejuni NCTC } \\
11168 \triangle \mathrm{cmeB}\end{array}$ & 0.016 & 0.062 & 16 \\
\hline $\begin{array}{l}\text { C. jejuni NCTC } \\
11168 \Delta c m e F\end{array}$ & 0.125 & 0.25 & 64 \\
\hline $\begin{array}{l}\text { C. jejuni NCTC } \\
11168 \Delta c m e R\end{array}$ & 0.25 & 0.5 & 64 \\
\hline
\end{tabular}




\subsection{Campylobacter Fitness under Pinocembrin Treatment}

The antimicrobial activity of pinocembrin on C. jejuni NCTC $11168 \Delta c m e R$ was further tested according to the time-kill kinetics of pinocembrin at the sub-inhibitory concentrations of $16 \mu \mathrm{g} / \mathrm{mL}$ $(0.25 \times \mathrm{MIC})$ and $32 \mu \mathrm{g} / \mathrm{mL}(0.5 \times \mathrm{MIC})$, at the MIC of $64 \mu \mathrm{g} / \mathrm{mL}$, and at the supra-inhibitory concentration of $128 \mu \mathrm{g} / \mathrm{mL}(2 \times \mathrm{MIC})$. The survival of the $\Delta c m e R$ mutant was significantly decreased by over $4 \log$ units at the MIC after $24 \mathrm{~h}$ of incubation at $42{ }^{\circ} \mathrm{C}$, in comparison to the untreated control, as seen from the growth curves shown in Figure 1. With the treatment of the double MIC pinocembrin, the bactericidal effects were seen already after $1 \mathrm{~h}$ of exposure of $C$. jejuni to pinocembrin, with the viability decreased by over $1 \log$ unit; after $6 \mathrm{~h}$, all of the $C$. jejuni were dead (Figure 1). Interestingly, the viability of the $\triangle c m e R$ mutant increased by $1 \log$ unit in the presence of both of the sub-inhibitory pinocembrin concentrations, as seen from the kinetics of the inactivation curves over $24 \mathrm{~h}$ (Figure 1).

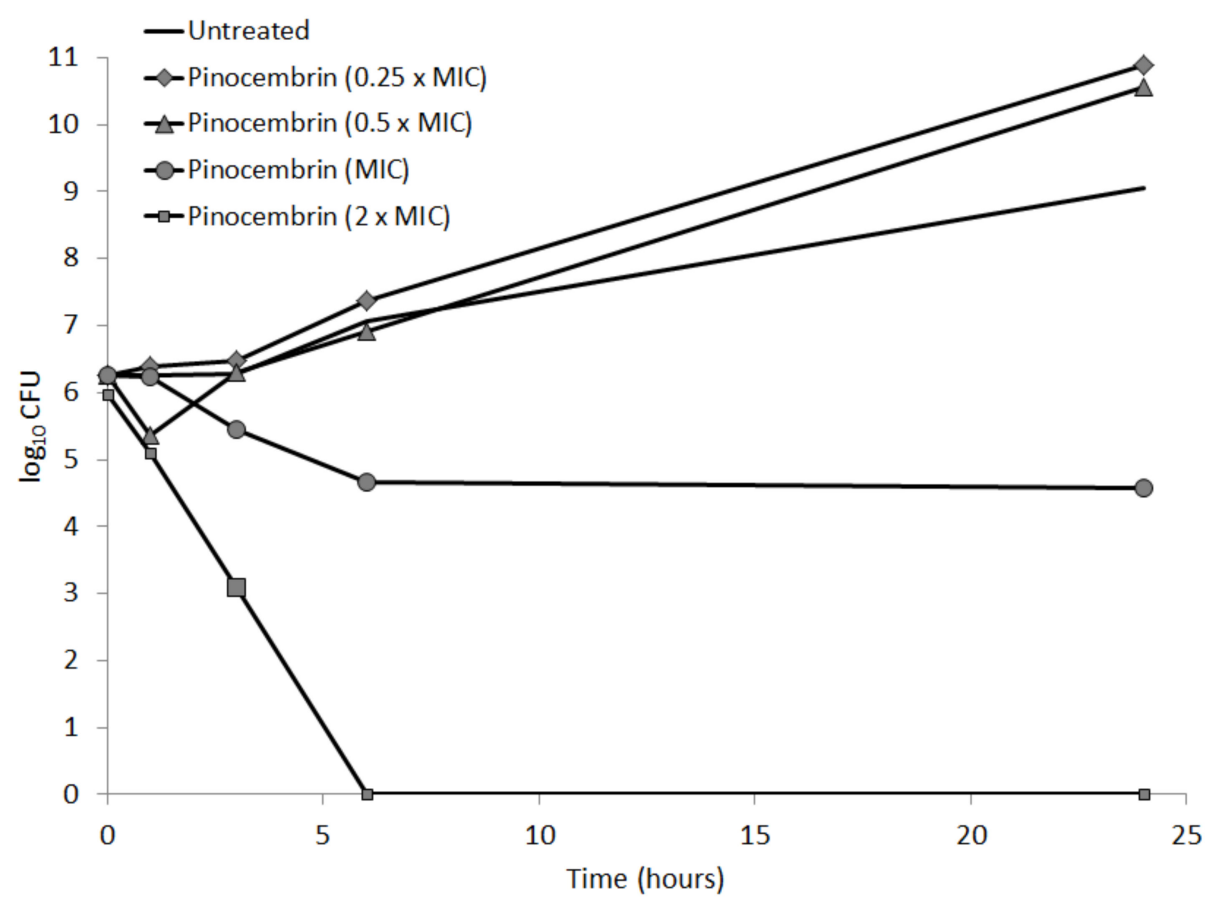

Figure 1. Time-kill kinetics of pinocembrin on C. jejuni NCTC $11168 \Delta \mathrm{cmeR}$ at the sub-inhibitory concentrations of $16 \mu \mathrm{g} / \mathrm{mL}(0.25 \times \mathrm{MIC})$ and $32 \mu \mathrm{g} / \mathrm{mL}(0.5 \times \mathrm{MIC})$, the inhibitory concentration of $64 \mu \mathrm{g} / \mathrm{mL}$ (MIC), and the supra-inhibitory concentration of $128 \mu \mathrm{g} / \mathrm{mL}(2 \times \mathrm{MIC})$, as indicated.

\subsection{Alterations of Campylobacter Membrane Integrity by Pinocembrin}

The influence of pinocembrin on C. jejuni NCTC $11168 \Delta c m e R$ membrane integrity was evaluated at the sub-inhibitory concentrations of $16 \mu \mathrm{g} / \mathrm{mL}(0.25 \times \mathrm{MIC})$ and $32 \mu \mathrm{g} / \mathrm{mL}(0.5 \times \mathrm{MIC})$, at the MIC of $64 \mu \mathrm{g} / \mathrm{mL}$, and at the supra-inhibitory concentration of $128 \mu \mathrm{g} / \mathrm{mL}(2 \times \mathrm{MIC})$. As expected, the highest pinocembrin (i.e., supra-inhibitory concentration) had large effects, with disruption of membrane integrity almost complete within $2 \mathrm{~h}(p<0.05)$. At the MIC of pinocembrin, the membrane permeability was increased by $77 \%$ compared to the untreated culture $(p<0.05)$. All of the sub-inhibitory pinocembrin concentrations significantly altered membrane permeability in comparison to the untreated control (Figure 2). 


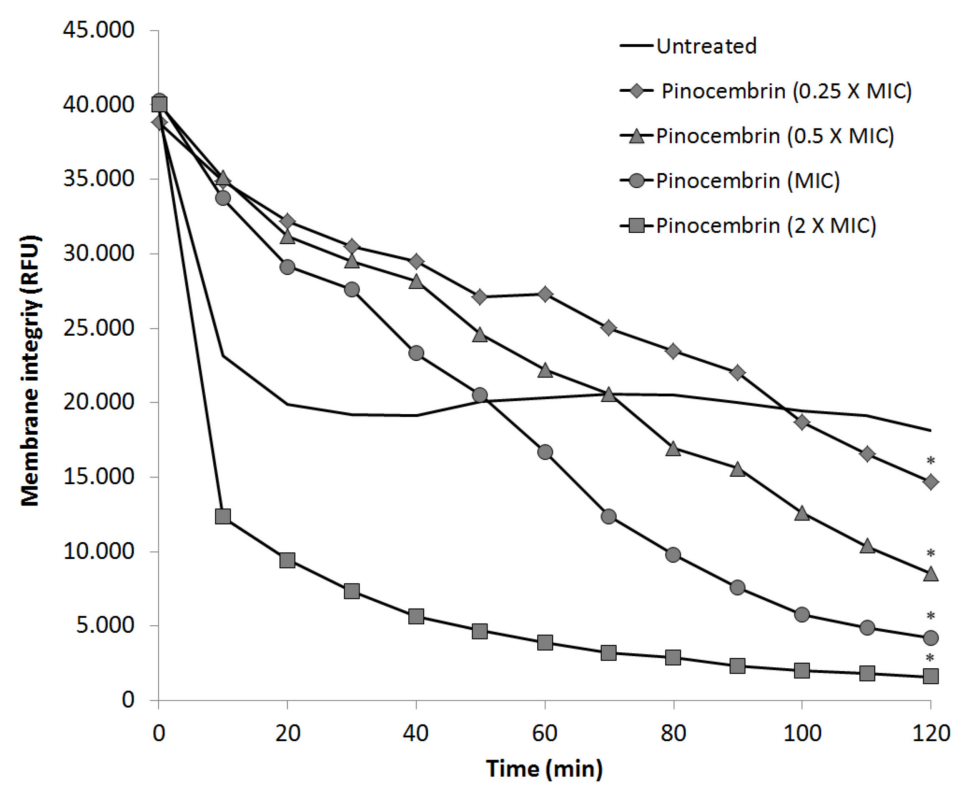

Figure 2. Influence of pinocembrin on membrane integrity of C. jejuni NCTC $11168 \Delta \mathrm{cmeR}$ after 2-h treatment at the sub-inhibitory concentrations of $16 \mu \mathrm{g} / \mathrm{mL}(0.25 \times \mathrm{MIC})$ and $32 \mu \mathrm{g} / \mathrm{mL}(0.5 \times \mathrm{MIC})$, at $64 \mu \mathrm{g} / \mathrm{mL}$ (MIC), and at the supra-inhibitory concentration of $128 \mu \mathrm{g} / \mathrm{mL}(2 \times \mathrm{MIC})$, as indicated. * $p<0.05$.

\subsection{Changes in Campylobacter Gene Expression by Pinocembrin}

To define other possible modes of pinocembrin activity in Campylobacter, we evaluated the Campylobacter responses to the sub-inhibitory pinocembrin concentration of $16 \mu \mathrm{g} / \mathrm{mL}(0.25 \times \mathrm{MIC})$. This treatment was expected to up-regulate the expression of genes in key pathways that are targeted by pinocembrin. After a 2-h treatment, 70 genes of NCTC $11168 \triangle c m e R$ were differentially transcribed (with cut-off set at $\geq 2$-fold difference; Table 2). Of these, 44 were up-regulated and 26 were down-regulated. The functional classification of these differentially expressed genes revealed that they were mainly involved in cell processes (23 genes), macromolecule metabolism (19 genes), and small molecule metabolism (16 genes).

The up-regulated genes after pinocembrin treatment were spread across 12 of the functional categories (Table 2, Supplementary Table S3), with most involved in small molecule metabolism (11) and macromolecule metabolism (10). For the small molecule metabolism, these genes were mostly involved in: energy metabolism (electron transport, aerobic metabolism); encoding of NADH dehydrogenase I (nuоN, nиоK, nиоL, nиоH); biosynthesis of co-cofactors, prosthetic groups, and carriers (molybdopterin, thiredoxin $\operatorname{tr} x A$, thiamine moeB); and amino-acid biosynthesis (serine family) and cysteine synthase (cysM). The $c j 1153$ gene was previously identified as a putative periplasmic cytochrome $C$ that is involved in energy metabolism and was strongly up-regulated in this study (4.16-fold). The up-regulated genes for macromolecule metabolism were involved in the cell envelope, inside the groups of: membranes, lipoproteins, and porins; surface polysaccharides, lipopolysaccharides, and antigens ( $p g l J)$; surface structures with several flagellum genes ( $f l i K, f l a C, f l g E 2, f l a A, f l g B, f l g D)$; and for a miscellaneous periplasmic protein ( $p 19)$. Among these, the serine protease $h t r A$ was also expressed, with a function in degradation of macromolecules, such as proteins, peptides, and glycopeptides. Under the broad regulatory functions, two genes were up-regulated in signal transduction processes. Interestingly, the most strongly up-regulated genes (Cj414, 9.04-fold; Cj415, 7.78-fold; Cj1338, 3.73-fold) showed miscellaneous functions (8 genes) and unknown functions (Table 2, Supplementary Table S3).

On the other hand, under this pinocembrin treatment, the down-regulated genes were scattered across eight functional categories (Table 2, Supplementary Table S3). Similarly, most of these genes were involved in cell processes (11), including transport/ binding proteins (amino acids and amines, 
carbohydrates, organic acids, alcohols) and pathogenicity. Cj0864 and Cj1358c were the most down-regulated genes, which encode a putative periplasmic protein (3.14-fold reduction), and a $n r f H$ putative periplasmic cytochrome C (2.73-fold reduction), respectively. Among the genes involved in macromolecule metabolism (9 genes), five ribosomal proteins were down-regulated $(r p s D, r p s K$, $r p s M, r p s A, r p m G)$, with two of these at higher levels ( $r p s A, r p m G$ : from 2.74-fold reduction to 2.87-fold reduction). Together with rRNA methylase ( $c s t A)$ and transcription anti-termination protein (nusG), these genes are involved in synthesis and modification of macromolecules: both ribosomal and RNA synthesis. Two membrane proteins belong to the group of the cell envelope. Five genes with functions in small molecule metabolism are involved in energy metabolism, mostly in electron transport (nrfG, $n r f A$, iron Sulphur protein). Interestingly, the highly down-regulated aspartate ammonia-lyse protein (aspA) (3.05-fold reduction) is involved in central intermediary metabolism, with a general function. Three down-regulated proteins show other functions (2 genes) or miscellaneous functions (1 gene).

Table 2. Differentially expressed genes after treatment of $C$. jejuni $11168 \Delta c m e R$ with pinocembrin $(16 \mu \mathrm{g} / \mathrm{mL}$, as $0.25 \times \mathrm{MIC})$.

\begin{tabular}{|c|c|c|c|}
\hline $\begin{array}{l}\text { Functional Classification of } \\
\text { Predicted C. jejuni Genes * }\end{array}$ & $\begin{array}{c}\text { Differentially } \\
\text { Expressed Genes (n) }\end{array}$ & $\begin{array}{l}\text { Up-Regulated } \\
\text { Genes (n) }\end{array}$ & $\begin{array}{l}\text { Down-Regulated } \\
\text { Genes (n) }\end{array}$ \\
\hline 1 Small molecule metabolism & 16 & 11 & 5 \\
\hline 1.B Energy metabolism & & 6 & 4 \\
\hline $\begin{array}{l}\text { 1.G Biosynthesis of cofactors, } \\
\text { prosthetic groups and carriers }\end{array}$ & & 4 & 0 \\
\hline 1.C Central intermediary metabolism & & 0 & 1 \\
\hline 1.D Amino acid biosynthesis & & 1 & 0 \\
\hline 2 Broad regulatory functions & 2 & 2 & 0 \\
\hline 2.1 Signal transduction & & 2 & \\
\hline 3 Macromolecule metabolism & 20 & 10 & 9 \\
\hline $\begin{array}{l}\text { 3.A Synthesis and modification of } \\
\text { macromolecules }\end{array}$ & & 0 & 7 \\
\hline 3.B Degradation of macromolecules & & 1 & 0 \\
\hline 3.C Cell envelope & & 9 & 2 \\
\hline 4 Cell processes & 23 & 12 & 11 \\
\hline 4.A Transport/binding proteins & & 4 & 2 \\
\hline 4.E Protein and peptide secretion & & 1 & 0 \\
\hline 4.G Detoxification & & 3 & 0 \\
\hline 4.I Pathogenicity & & 4 & 7 \\
\hline 5 Other & 3 & 1 & 2 \\
\hline 5.H Conserved hypothetical proteins & & 1 & 2 \\
\hline 6. Miscellaneous & 9 & 8 & 1 \\
\hline Total & 73 & & \\
\hline
\end{tabular}

* Classification is based on that used for Escherichia coli by Riley, M. and Labedan, B. in Escherichia coli and Salmonella (ed. Neidhardt, F.C.) 2118-2202 (ASM, Washington, 1996) [21].

With qRT-PCR, up-regulation was confirmed for the superoxide dismutase $(\mathrm{Fe})(\operatorname{sodB})$ gene and the putative flagellar hook assembly protein $(f l g D)$, and down-regulation was confirmed for three genes, namely the $30 \mathrm{~S}$ ribosomal protein $\mathrm{S} 4(\mathrm{rps} D)$, carbon starvation protein A homologue with putative function as an integral membrane protein $(\operatorname{cst} A)$, and putative periplasmic cytochrome $\mathrm{C}(n r f H)$. These three genes (cst $A, \operatorname{asp} A, n r f H)$ have important functions in macromolecule metabolism, small molecule 
metabolism, and cell processes, respectively, and they were strongly down-regulated by more than 2.5-fold reduction.

\subsection{Intracellular ROS Formation}

To confirm that oxidative stress was one of the key mechanisms of the pinocembrin antimicrobial activity, as suggested by the gene expression analyses, the intracellular levels of ROS were determined after treatment of $C$. jejuni NCTC $11168 \Delta c m e R$ with $0.25 \times$ MIC pinocembrin. The results did not confirm oxidative stress as one of the key antimicrobial mechanisms. The differences in intracellular levels of ROS between the treated and untreated cultures were not significant $(p=0.266)$ (Supplementary Figure S1).

\subsection{Inhibition of Pinocembrin Activity with Fe Chelator 2,2-Dipyridyl}

To examine the influence of pinocembrin on hydroxyl radical formation, we tested the viability of the C. jejuni $11168 \Delta c m e R$ cultures under treatment with pinocembrin and 2,2-dipyridyl. 2,2-Dipyridyl is an iron chelator that can reduce harmful hydroxyl radicals generated in the Fenton reaction [22]. We found a significant influence of 2,2-dipyridyl on the pinocembrin action, especially after $24 \mathrm{~h}$ of treatment. The viabilities of the $C$. jejuni cultures treated with the combination of pinocembrin at the inhibitory concentration of $64 \mu \mathrm{g} / \mathrm{mL}$ plus 2,2-dipyridyl were significantly $(p<0.05)$ higher compared to those treated with the pinocembrin alone. Pinocembrin decreased C. jejuni NCTC $11168 \Delta c m e R$ viability by $2 \log$ units after $24 \mathrm{~h}$, which was decreased to $1 \log$ unit with the addition of 2,2-dipyridyl. Treatment with 2,2-dipyridyl alone increased the viability by $0.5 \log$ unit compared to the untreated C. jejuni cultures (Figure 3).

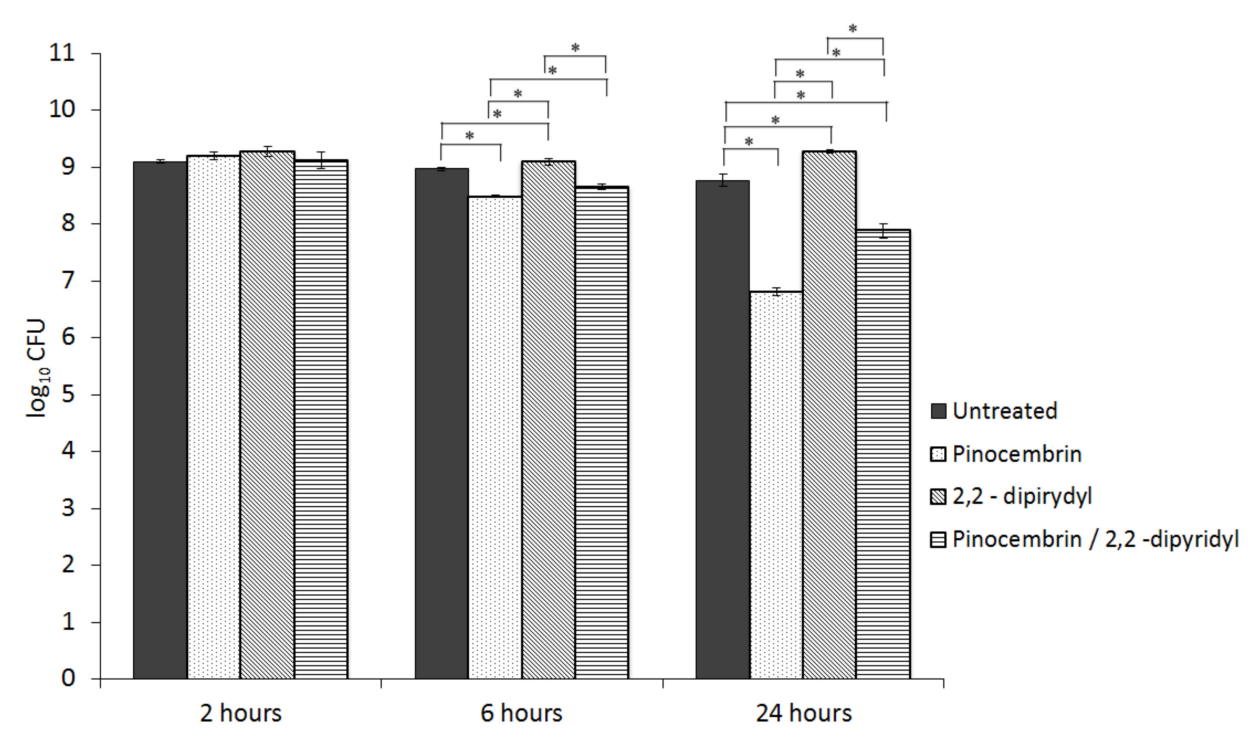

Figure 3. Inhibition of the pinocembrin $(64 \mu \mathrm{g} / \mathrm{mL}$; MIC) antibacterial activity on C. jejuni NCTC $11168 \Delta \mathrm{cmeR}$ with the iron chelator 2,2-dipyridyl $(78 \mu \mathrm{g} / \mathrm{mL})$, as indicated. ${ }^{*}, p<0.05$.

\subsection{Modulation of Campylobacter Motility}

The influence of pinocembrin on the motility of $C$. jejuni NCTC $11168 \Delta c m e R$ was measured on soft agar, as compared to untreated cells. After 2-h treatment with the sub-inhibitory pinocembrin concentration of $0.5 \times \mathrm{MIC}$, the $C$. jejuni motility increased significantly. The diameter of the untreated C. jejuni cultures was $21.2 \pm 1.6 \mathrm{~mm}$, whereas after the pinocembrin treatment, this was $31.0 \pm 1.9 \mathrm{~mm}$ (Table 3). 
Table 3. Influence of pinocembrin on C. jejuni NCTC $11168 \Delta \mathrm{cmeR}$ motility on soft agar after 2-h treatment at the sub-inhibitory concentrations of $16 \mu \mathrm{g} / \mathrm{mL}(0.25 \times \mathrm{MIC})$ and $32 \mu \mathrm{g} / \mathrm{mL}(0.5 \times \mathrm{MIC})$, as indicated. Data are means \pm standard deviation for the diameter measured on the agar plate.

\begin{tabular}{cc}
\hline C. jejuni NCTC $\mathbf{1 1 1 6 8 \Delta} \mathbf{c m e R}$ & Diameter $(\mathbf{m m})$ \\
\hline Untreated & $21.2 \pm 1.57$ \\
Pinocembrin $(0.25 \times \mathrm{MIC})$ & $19 \pm 0.81$ \\
Pinocembrin $(0.5 \times \mathrm{MIC})$ & $31 \pm 1.91^{\mathrm{a}}$ \\
\hline a $p<0.05$ (vs. untreated control)
\end{tabular}

\subsection{Modulation of Campylobacter Virulence under Pinocembrin Treatment}

The influence of the sub-inhibitory pinocembrin concentration $(32 \mu \mathrm{g} / \mathrm{mL} ; 0.5 \times \mathrm{MIC})$ on C. jejuni virulence was tested in a murine model. Four groups of BALB/c mice were intravenously infected with C. jejuni NCTC 11168 wild-type and the C. jejuni NCTC $11168 \triangle c m e R$ mutant, as either untreated or pre-treated with the sub-inhibitory concentration of pinocembrin. After an initial and significant rise in the number of $C$. jejuni isolated for the third day post-infection, at eight days post-infection, the number of $C$. jejuni recovered from the mice livers in the pinocembrin-treated group diminished significantly in comparison to the untreated control (Figure 4).

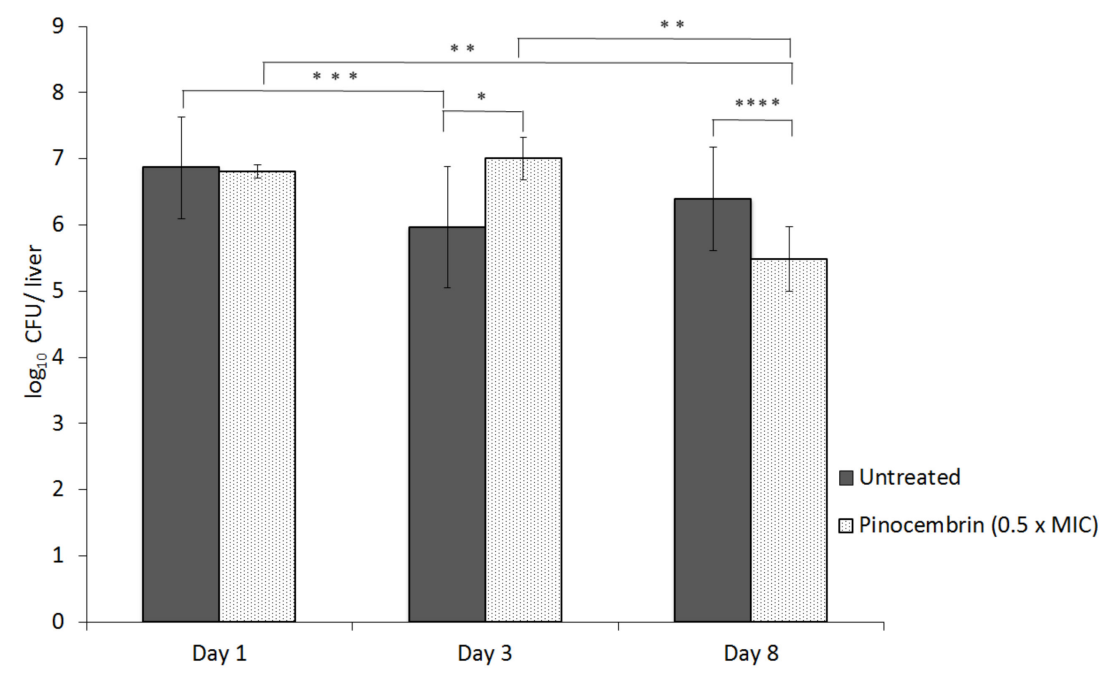

Figure 4. Influence of pinocembrin on C. jejuni NCTC $11168 \Delta c m e R$ in the livers of BALB/c mice. The mice were intravenously infected with untreated C. jejuni NCTC $11168 \Delta$ cmeR or C. jejuni NCTC $11168 \Delta \mathrm{cmeR}$ treated with pinocembrin at the sub-inhibitory concentration of $32 \mu \mathrm{g} / \mathrm{mL}(0.5 \times \mathrm{MIC})$, as indicated. Data are means \pm standard deviation of $C$. jejuni colony-forming units (CFU)/liver. ${ }^{*}, p=0.006,{ }^{* *}, p=0.012,{ }^{* * *}, p=0.018$ and ${ }^{* * *}, p=0.024$.

\section{Discussion}

We have demonstrated antimicrobial activity of pinocembrin against $C$. jejuni and indicated possible mechanisms of its action. Specific intracellular sites of action and derivative targets would need to be further investigated to fully understand the mechanism of the mode of action of pinocembrin. Pinocembrin can potentially be used for medical applications or to serve as a chemical template for the design, synthesis and semi-synthesis of new substances for treatment of human Campylobacter infections [5,7].

In the present study, we first characterized the anti-Campylobacter activity of pinocembrin and defined the specific roles of the $\mathrm{CmeABC}$ and $\mathrm{CmeDEF}$ efflux pumps in resistance to pinocembrin. The 4-fold decrease in MIC of the mutant defective in $c m e B$, compared to wild-type, indicates possible involvement of the CmeABC efflux pump in the resistance against pinocembrin. The disruption of 
cmeF and cmeR did not have any effects on the MIC, which indicated that the CmeDEF efflux pump is not likely to be involved in Campylobacter protection against pinocembrin when CmeABC functions normally. These data are consistent with a previous study of Klančnik et al. [9], where the CmeABC efflux pump was shown to be an important resistance mechanism against plant extracts and phenolic compounds in $C$. jejuni. Therefore, further experiments were carried out on a null mutant in a cmeABC transcriptional repressor $(\Delta c m e R)$ that models an intrinsically resistant strain.

To determine the kinetics of pinocembrin on C. jejuni NCTC $11168 \Delta c m e R$, growth was tested at sub-inhibitory, inhibitory, and supra-inhibitory pinocembrin concentrations. These data confirmed pinocembrin as a bacteriostatic antimicrobial that sufficiently prevents growth at the MIC and significantly decreases viability at a supra-inhibitory concentration. Conversely, sub-inhibitory concentrations enhanced bacterial fitness.

Antibiotics targeting intracellular processes must penetrate the bacterial cell envelope. This applies in particular to the outer membrane of gram-negative bacteria, as this provides a formidable barrier [23]. We have shown here that pinocembrin affects the membrane integrity at inhibitory and sub-inhibitory concentrations, and that the effects observed are concentration dependent. As pinocembrin can increase membrane permeability and also act as an antimicrobial, it might be suitable for use in combination with other antimicrobials with low membrane permeability, to achieve synergistic effects. Sub-inhibitory concentrations of pinocembrin only slightly modulated Campylobacter membrane permeability and thus we can conclude that at sub-inhibitory concentrations, pinocembrin does not significantly decrease cell viability, but promotes bacterial growth and increases bacterial fitness. The up-regulation of 11 genes and down-regulation of 5 genes after exposure of $C$. jejuni to pinocembrin might indicate that pinocembrin treatment induces stress responses in Campylobacter cells. Additionally, the higher number of up-regulated genes involved in energy metabolism suggests stress responses [24]. Further, nine up-regulated genes involved in cell envelope synthesis indicate possible envelope stress responses [25].

These findings led us to investigate the effects of a sub-inhibitory concentration of pinocembrin on gene expression in C. jejuni NCTC $11168 \Delta c m e R$ using microarrays and qRT-PCR. The most significantly up-regulated genes ( $>7$-fold) were putative oxidoreductase subunits of unknown function (Cj0414, Cj0415). These two co-transcribed genes encode the two components of gluconate-oxidizing oxidoreductase, which is predicted to be localized in the periplasm, to peripherally associate with the cytoplasmic membrane, and to transfer electrons to periplasmic cytochrome c [26]. Up-regulation of these genes was seen also in response to acid shock, but it is not clear how this activity would contribute to the $C$. jejuni acid-shock response [27]. The changed transcription of a larger number of important genes points to a wider systemic response of $C$. jejuni in the presence of pinocembrin. We note here the significance of molybdoproteins Cj0725c, Cj0379c, and Cj1046-moeB, as these are also important in competition with the host microbiota. Moreover, for the genes involved in respiratory functions, as for the putative periplasmic cytochrome $\mathrm{C}$ (cj1153), which is important in defense against $\mathrm{H}_{2} \mathrm{O}_{2}$ through the reduction and detoxification of exogenous $\mathrm{H}_{2} \mathrm{O}_{2}$ [28,29]. Similarly, for the $\mathrm{C} 551$ peroxidase $\mathrm{Cj} 0358$, as one of the most down-regulated genes (2.89-fold reduction), which confirms that it is not significant in the resistance of $C$. jejuni against $\mathrm{H}_{2} \mathrm{O}_{2}[28,30]$. On the other hand, two periplasmic cytochrome $\mathrm{C}$ proteins $n r f A(\mathrm{Cj} 1357 \mathrm{c})$ and $n r f H(\mathrm{Cj} 1358 \mathrm{c})$, and the putative ferredoxin nap G (Cj0781; known as periplasmic located Nap-type nitrate reductase) were down-regulated in this study, which will disable nitrate as an electron acceptor in C. jejuni and further the reduction of nitrate to nitrite [30,31].

Up-regulation of the oxidative stress response genes $\operatorname{sodB}, a h p C$, and t $p x$ observed in the microarray study here indicates that pinocembrin treatment generates toxic ROS, like hydroxyl $(\mathrm{OH})$ and superoxide $\left(\mathrm{O}^{-}{ }_{2}\right)$ radicals, as well as hydrogen peroxide $\left(\mathrm{H}_{2} \mathrm{O}_{2}\right)$. Increased ROS causes damage to DNA, membranes, and proteins in the bacterial cell [32]. Consequently, a variety of ROS-detoxifying enzymes were expressed at the highest levels, which included the alkyl hydroxide reductase AhpC [33], superoxide dismutase SodB [34], and the thiolperoxidases Tpx [31,35]. The expression of oxidative stress defense genes in C. jejuni (e.g., $d p s, \operatorname{sod} B, \operatorname{trx} B, \operatorname{ahpC}$ ) was shown to increase also by exposure to $\mathrm{HCl}$ or acetic acid [36,37], which links the oxidative stress response mechanism and the acid-shock 
response in C. jejuni [27]. Additionally, the serine protease $h \operatorname{tr} A$ (Cj1228c), required for heat and oxygen tolerance [38], was up-regulated, which indicated that it might be important for protection against pinocembrin treatment. As is known, these genes are also important to counteract oxidative and other stresses for optimal interactions with human epithelial cells, and during the host colonization processes of C. jejuni [38-41]. Recently, Kendall et al. [42] indicated that the OORC subunit of 2-oxoglutarate:acceptor oor $C$ is one of the important genes involved in oxygen tolerance of $C$. jejuni. This gene (oorC; cj0538) was also up-regulated by pinocembrin.

This led us to investigate the phenotypic effects of pinocembrin on intracellular ROS formation and the decrease in hydroxyl radical formation by an iron chelator, which might explain the pinocembrin killing mechanism. Increased ROS levels in cells might indicate that oxidation occurs and antioxidant defense systems are a target of pinocembrin action. Previous studies of pinocembrin have shown its antioxidative activity in vitro as well as in vivo [43], while others have reported that it can cause oxidative damage in the presence of transition metal ions [44]. The underlying mechanism is thus relatively complex and no significantly decreased intracellular oxidation was observed in the present study. This might have been due to the mild oxidative stress caused by pinocembrin, rather than to its antioxidative activity. According to the results of our transcriptional study, weak oxidative stress induces the expression of oxidative stress defense genes. The higher levels of defensive enzymes can therefore efficiently neutralize ROS, which provides a protective effect that is reflected as ROS inhibition and time-kill kinetics. Furthermore, we confirmed the involvement of oxidative stress in the pinocembrin antibacterial activity by using 2,2-dipyridyl, an iron chelator that is involved in decreasing hydroxyl radical formation in the Fenton reaction When the $C$. jejuni cultures were treated with the combination of pinocembrin and 2,2-dipyridyl, the $C$. jejuni numbers compared to the treatment with only pinocembrin were halved. However, 2,2-dipyridyl did not counteract the effects of pinocembrin completely, which confirmed that oxidative stress is only part of the mechanism of pinocembrin. The involvements of other mechanisms together with oxidative stress, such as membrane disruption, are key mechanisms in the antimicrobial activity of pinocembrin.

It is known that as well as serine, proline, and glutamate catabolism, aspartate is crucial for the metabolic fitness of $C$. jejuni [45]. In the present study, down-regulated expression was seen for the C4-dicarboxylate transporter gene $d c u B$ (Cj0671) and the aspartase gene aspA (Cj0087), both of which are important for persistence of $C$. jejuni in its host [44,45]. Down-regulation with pinocembrin was also seen for the putative HAMP-containing membrane protein Cj0952c, which affects chemotactic behavior towards formic acid and is important for invasion of host cells [45], the Cj0073c gene, which is important for NAD-independent respiratory lactate dehydrogenase activity, and the Cj0903c gene, which is a gene for putative amino-acid transporters with homology to members of the sodium:alanine symporter family with unknown substrate specificity [45]. The down-regulation of ribosomal proteins observed with pinocembrin treatment correlated with the lower levels required for protein synthesis and biosynthesis of amino acids, purines and fatty acids during the extended intracellular persistence inside the Campylobacter-containing vacuole. Further, several protein-degrading and peptide-degrading proteins and transporters involved in the uptake of amino acids, phosphate, and metals showed lower levels $20 \mathrm{~h}$ post-infection [45]. In contrast, a transporter involved in the uptake of iron $c f b p A$ (Cj0175c) was up-regulated under pinocembrin.

The C. jejuni bipolar flagellum is particularly important for its motility. Interestingly, under pinocembrin treatment, the up-regulated proteins are involved in all three conserved parts of the bipolar flagellum; namely, the basal body, hook, and filament. In the present study, flagellin flaA (Cj1139c) was up-regulated, which is one of two flagellins (FlaA, FlaB) of the flagellar filament [28,46]. The flagellar channel serves as a non-conventional type III secretion system that is necessary for the export of the adhesive protein FlaC that influences invasion and interactions with the host environment [46]. This flagellin gene $f l a C$ (CjO720c) was up-regulated by 2.22-fold under pinocembrin treatment. Similarly, there was up-regulation of some flagellar hook protein regulatory genes: fliK (Cj0041), which encodes a hook length control and export specificity switch, and $f l g D$ (Cj0042) and $f l g E$ (Cj1729c), which have 
important roles in motility, flagellar filament assembly, hook assembly, and regulation of flagellin synthesis and secretion [47]. The basal body constitutes a major portion of the flagellar organelle and consists of a number of rings that are mounted on a central rod [46]. The gene flgB (Cj0528c) encodes the flagellar basal body rod protein FlgB and this was up-regulated 2.15-fold under pinocembrin treatment. Furthermore, Gaynor et al. [48] reported that protein misfolding and degradation are consistent with a stress-related response to misdirection of the assembly of the flagellum.

In Campylobacter, flagellar biosynthesis is co-regulated with virulence [46], making motility a major virulence factor in its infection and pathogenesis $[49,50]$. We confirmed the data from the transcriptomic analysis at a phenotypic level, with significantly increased Campylobacter motility after pinocembrin treatment. This confirmed the importance of up-regulated genes involved in flagellar assembly and motility after pinocembrin treatment. Up-regulation of flagellar genes and increased motility in Campylobacter have been linked to acid-shock exposure [51]. In agreement with this, in acid-shocked Campylobacter there is increased expression of flagellar biosynthetic genes, as genes involved in oxidative and general stress responses. This response presents a problem, as acid shock in Campylobacter not only increases their motility, but also increases their passing through the acidic gastric environment and their ability to invade the $\mathrm{m}-\mathrm{IC}_{\mathrm{cl} 2}$ mouse small intestine crypt cells [51].

We noted that under pinocembrin treatment, C. jejuni $\triangle c m e R$ showed up-regulation of the expression of heat-shock, acid-shock, and oxygen stress response genes. It is known that the flagellum (basal body, hook, and filament portions) and also the heat-shock response in C. jejuni influences colonization of a chicken host $[40,52,53]$. In the present study, we investigated the systemic infection of BALB/c mice with pinocembrin-treated C. jejuni $\Delta c m e R$. On the third day after infection, the number of pinocembrin-treated Campylobacter was higher than that in the control group, which can be explained by the up-regulation of motility-associated proteins, including fla $\mathrm{A}$, flaC, and $f l i K$, and stress-response genes that contribute to the resistance of $C$. jejuni in the host environment. Despite this initial increase, there were later reductions in the bacterial numbers in the liver of the host, with a drop in numbers by the eighth day post-infection, which makes the advantage at day three a temporary phenomenon. This suggests increased sensitivity of pinocembrin-treated Campylobacter to the host immune response. Consequently, pinocembrin-treated C. jejuni cells were less likely to persist in the host.

\section{Conclusions}

In conclusion, pinocembrin, a compound naturally occurring in foods such as honey, shows antimicrobial activity towards Campylobacter through reduction of membrane integrity. However, this activity is lost at a sub-inhibitory concentration of pinocembrin, which also, in contrast, promotes bacterial growth and increases bacterial fitness. The subinhibitory concentration of pinocembrin modified transcription of Campylobacter genes involved in cell-wall synthesis, heat-shock, acid-shock, and oxidative-stress, which is likely to result in improved fitness, membrane integrity and oxidative stress defense.

Supplementary Materials: The following are available online at http://www.mdpi.com/2076-2607/7/12/675/s1: Figure S1: Time-course of influence of sub-inhibitory pinocembrin $(16 \mu \mathrm{g} / \mathrm{mL} ; 0.25 \times \mathrm{MIC})$ on intracellular reactive oxygen species in Campylobacter jejuni NCTC 11168 $\mathrm{cmeR}$; Table S1: Primers of the genes for qRT-PCR confirmation used in this study; Table S2: Antimicrobial activity of ciprofloxacin (CIP; $5 \mu \mathrm{g}$ ), erythromycin (ERY $15 \mu \mathrm{g})$ and pinocembrin (Pc $100 \mu \mathrm{g}, 50 \mu \mathrm{g}, 25 \mu \mathrm{g}, 12.5 \mu \mathrm{g}$ ) against $C$. jejuni NCTC 11168 and its efflux pump knockout mutant strains lacking the functional genes for efflux pumps CmeABC $(\triangle c m e B)$ and $\mathrm{CmeDEF}(\triangle c m e F)$, and the efflux pump repressor $\mathrm{CmeR}(\Delta c m e R)$, presented as inhibition zone diameters $(\mathrm{mm})$; Table S3: Differentially expressed genes after treatment of $C$. jejuni $11168 \Delta c m e R$ with pinocembrin $(0.25 \times \mathrm{MIC})$.

Author Contributions: Conceived and designed the experiments: A.K., J.K., O.S., Z.W., D.V., and Q.Z.; performed the experiments: A.K., K.Š., J.K., and O.S; analyzed the data: A.K., K.Š., J.K, O.S., W.U., D.V., and Q.Z.; contributed reagents/materials/analysis tools: A.K., S.S.M., M.A., and Q.Z. Wrote the paper: A.K., K.Š., J.K, O.S., Z.W., D.V., M.A., Q.Z., and S.S.M.

Funding: The study was funded by the Slovenian Research Agency (Grant No. P4-0116, J4-9299), and bilateral SI-USA projects. 
Conflicts of Interest: The authors declare no conflict of interest.

\section{References}

1. EFSA. The European Union summary report on trends and sources of zoonoses, zoonotic agents and food-borne outbreaks in 2016. EFSA J. 2017, 15, 5077.

2. Nyati, K.K.; Nyati, R. Role of Campylobacter jejuni infection in the pathogenesis of Guillain-Barré syndrome: an update. Biomed. Res. Int. 2013, 859125. [CrossRef]

3. ECDC. Antimicrobial Resistance in Zoonotic Bacteria Still High in Humans, Animals and Food, Say ECDC and EFSA. European Centre for Disease Prevention and Control (ECDC). 2018. Available online: https://www.ecdc.europa.eu/en/news-events/antimicrobial-resistance-zoonotic-bacteria-still-highhumans-animals-and-food-say-ecdc (accessed on 9 December 2019).

4. Friedman, M. Antibiotic-resistant bacteria: prevalence in food and inactivation by food-compatible compounds and plant extracts. J. Agric. Food Chem. 2015, 63, 3805-3822. [CrossRef] [PubMed]

5. Lan, X.; Wang, W.; Li, Q.; Wang, J. The natural flavonoid pinocembrin: Molecular targets and potential therapeutic applications. Mol. Neurobiol. 2016, 53, 1794-1801. [CrossRef] [PubMed]

6. Aiello, F.; Armentano, B.; Polerà, N.; Carullo, G.; Loizzo, R.M.; Bonesi, M.; Cappello, M.S.; Capobianco, L.; Tundis, R. From vegetable waste to new agents for potential health applications: Antioxidant properties and effects of extracts, fractions and pinocembrin from Glycyrrhiza glabra L. aerial parts on viability of five human cancer cell lines. J. Agric. Food Chem. 2017, 65, 7944-7954. [CrossRef] [PubMed]

7. Rasul, A.; Millimouno, F.M.; Ali Eltayb, W.; Ali, M.; Li, J.; Li, X. Pinocembrin: a novel natural compound with versatile pharmacological and biological activities. Biomed. Res. Int. 2013, 203, 1-9. [CrossRef]

8. Lin, J.; Overbye, M.L.; Zhang, Q. CmeABC functions as a multidrug efflux system in Campylobacter jejuni. Antim. Agents Chemotherap. 2002, 46, 2124-2131. [CrossRef]

9. Klančnik, A.; Smole Možina, S.; Zhang, Q. Anti-Campylobacter activities and resistance mechanisms of natural phenolic compounds in Campylobacter. PLoS ONE 2012, 7, e51800. [CrossRef]

10. Lin, J.; Akiba, M.; Sahin, O.; Zhang, Q. CmeR functions as a transcriptional repressor for the multidrug efflux pump CmeABC in Campylobacter jejuni. Antim. Agents Chemotherap. 2005, 49, 1067-1075. [CrossRef]

11. Yang, W.; Zhang, M.; Zhou, J.; Pang, L.; Wang, G.; Hou, F. The molecular mechanisms of ciprofloxacin resistance in clinical Campylobacter jejuni and their genotyping characteristics in Beijing, China. Foodborne Pathog. Dis. 2017, 14, 386-392. [CrossRef]

12. Zhang, T.; Cheng, Y.; Luo, Q.; Lu, Q.; Dong, J.; Zhang, R.; Wen, G.; Wang, H.; Luo, L.; Wang, H.; et al. Correlation between gyrA and CmeR box polymorphism and fluoroquinolone resistance in Campylobacter jejuni isolates in China. Antimicrob. Agents Chemoth. 2017, 61, e00422-17. [CrossRef] [PubMed]

13. Lekshmi, M.; Ammini, P.; Kumar, S.; Varela, M.F. The food production environment and the development of antimicrobial resistance in human pathogens of animal origin. Microorganisms 2017, 5, 11. [CrossRef] [PubMed]

14. Klančnik, A.; Guzej, B.; Hadolin Kolar, M.; Abramovič, H.; Smole Možina, S. In-vitro antimicrobial and antioxidant activity of commercial rosemary extract formulations. J. Food Prot. 2009, 72, 1744-1752. [CrossRef] [PubMed]

15. EUCAST 2019. The European Committee on Antimicrobial Susceptibility Testing. Breakpoint tables for interpretation of MICs and zone diameters. Version 9.0, 2019. Available online: http://www.eucast.org/ fileadmin/src/media/PDFs/EUCAST_files/Breakpoint_tables/v_9.0_Breakpoint_Tables.pdf (accessed on 15 October 2019).

16. Klančnik, A.; Piskernik, S.; Jeršek, B.; Smole Možina, S. Evaluation of diffusion and dilution methods to determine the antibacterial activity of plant extracts. J. Microbiol. Methods 2010, 81, 121-126. [CrossRef]

17. Kovač, J.; Šimunović, K.; Wu, Z.; Klančnik, A.; Bucar, F.; Zhang, Q. Smole Možina, S. Antibiotic resistance modulation and modes of action of (-)- $\alpha$-pinene in Campylobacter jejuni. PLoS ONE 2015, 10, e0122871. [CrossRef]

18. Livak, K.J.; Schmittgen, T.D. Analysis of relative gene expression data using real-time quantitative PCR and the 2(-Delta Delta C(T)) method. Methods 2001, 25, 402-408. [CrossRef]

19. Klančnik, A.; Vučković, D.; Plankl, M.; Abram, M.; Smole Možina, S. In-vivo modulation of Campylobacter jejuni virulence in response to environmental stress. Foodborne Pathog. Dis. 2013, 10, 6. [CrossRef] 
20. Wu, Z.; Sahin, O.; Shen, Z.; Liu, P.; Miller, W.G.; Zhang, Q. Multi-omics approaches to deciphering a hypervirulent strain of Campylobacter jejuni. Genome Biol. Evol. 2013, 5, 2217-2230. [CrossRef]

21. Riley, M.; Labedan, B. Gene products: physiological functions and common ancestries. In Escherichia coli and Salmonella: Cellular and Molecular Biology, 2nd ed.; Neidhardt, F.C., Curtiss, R., III, Ingraham, J.L., Lin, E.C.C., Low, K.B., Magasanik, B., Reznikoff, W.S., Riley, M., Schaechter, M., Umbarger, H.E., Eds.; ASM Press: Washington, DC, USA, 1996; pp. 2118-2202.

22. Kohanski, M.A.; Dwyer, D.J.; Hayete, B.; Lawrence, C.A.; Collins, J.J. A common mechanism of cellular death induced by bactericidal antibiotics. Cell 2007, 130, 797-810. [CrossRef]

23. Delcour, A.H. Outer membrane permeability and antibiotic resistance. Biochim. Biophys. Acta 2009, 1794, 808-816. [CrossRef]

24. Schwachtje, J.; Whitcomb, S.J.; Firmino, A.A.P.; Zuther, E.; Hincha, D.K.; Kopka, K. Induced, Imprinted, and primed responses to changing environments: Does metabolism store and process information? Front. Plant Sci. 2019, 10, 106. [CrossRef] [PubMed]

25. Hews, C.L.; Cho, T.; Rowley, G.; Raivio, T.L. Maintaining integrity under stress: envelope stress response regulation of pathogenesis in gram-negative bacteria. Front. Cell. Infect. Microbiol. 2019, 9, 31. [CrossRef] [PubMed]

26. Pajaniappan, M.; Hall, J.E.; Cawthraw, S.A.; Newell, D.G.; Gaynor, E.C.; Fields, J.A.; Rathbun, K.M.; Agee, W.A.; Burns, C.M.; Hall, S.J.; et al. A temperature-regulated Campylobacter jejuni gluconate dehydrogenase is involved in respiration-dependent energy conservation and chicken colonization. Mol. Microbiol. 2008, 68, 474-491. [CrossRef] [PubMed]

27. Reid, A.N.; Pandey, R.; Palyada, K.; Naikare, H.; Stintzi, A. Identification of Campylobacter jejuni genes involved in the response to acidic $\mathrm{pH}$ and stomach transit. Appl. Environ. Microbiol. 2008, 74, 1583-1597. [CrossRef]

28. Hendrixsonm, D.R.; DiRitam, V.J. Identification of Campylobacter jejuni genes involved in commensal colonization of the chick gastrointestinal tract. Mol. Microbiol. 2004, 52, 471-484. [CrossRef]

29. Sellars, M.J.; Hall, S.J.; Kelly, D.J. Growth of Campylobacter jejuni supported by respiration of fumarate, nitrate, nitrite, trimethylamine-N-oxide, or dimethyl sulfoxide requires oxygen. J. Bacteriol. 2002, 184, 4187-4196. [CrossRef]

30. Bingham-Ramos, L.K.; Hendrixson, D.R. Characterization of two putative cytochrome c peroxidases of Campylobacter jejuni involved in promoting commensal colonization of poultry. Infect. Immun. 2008, 76, 1105-1114. [CrossRef]

31. Kim, J.-C.; Oh, E.; Kim, J.; Jeon, B. Regulation of oxidative stress resistance in Campylobacter jejuni, a microaerophilic foodborne pathogen. Front. Microbiol. 2015, 6, 751. [CrossRef]

32. Pittman, M.S.; Elvers, K.T.; Lee, L.; Jones, M.A.; Poole, R.K.; Park, S.F.; Kelly, D.J. Growth of Campylobacter jejuni on nitrate and nitrite: electron transport to NapA and NrfA via NrfH and distinct roles for NrfA and the globin Cgb in protection against nitrosative stress. Mol. Microbiol. 2007, 63, 575-590. [CrossRef]

33. Baillon, M.L.; Van Vliet, A.H.; Ketley, J.M.; Constantinidou, C.; Penn, C.W. An iron-regulated alkyl hydroperoxide reductase (AhpC) confers aerotolerance and oxidative stress resistance to the microaerophilic pathogen Campylobacter jejuni. J. Bacteriol. 1999, 181, 4798-4804. [PubMed]

34. Pesci, E.C.; Cottle, D.L.; Pickett, C.L. Genetic, enzymatic, and pathogenic studies of the iron superoxide dismutase of Campylobacter jejuni. Infect. Immun. 1994, 62, 2687-2694. [PubMed]

35. Atack, J.M.; Kelly, D.J. Contribution of the stereospecific methionine sulphoxide reductases MsrA and MsrB to oxidative and nitrosative stress resistance in the food-borne pathogen Campylobacter jejuni. Microbiology 2008, 154, 2219-2230. [CrossRef] [PubMed]

36. Murphy, C.; Carroll, C.; Jordan, K.N. Induction of an adaptive tolerance response in the foodborne pathogen, Campylobacter jejuni. FEMS Microbiol. Lett. 2003, 23, 89-93. [CrossRef]

37. Birk, T.; Wik, M.T.; Lametsch, R.; Knøchel, S. Acid stress response and protein induction in Campylobacter jejuni isolates with different acid tolerance. BMC Microbiol. 2012, 12, 174. [CrossRef] [PubMed]

38. Brøndsted, L.; Andersen, M.T.; Parker, M.; Jørgensen, K.; Ingmer, H. The HtrA protease of Campylobacter jejuni is required for heat and oxygen tolerance and for optimal interaction with human epithelial cells. Appl. Environ. Microbiol. 2005, 71, 3205-3212. [CrossRef]

39. Novik, V.; Hofreuter, D.; Galán, J.E. Identification of Campylobacter jejuni genes involved in its interaction with epithelial cells. Infect. Immun. 2010, 78, 3540-3553. [CrossRef] 
40. Palyada, K.; Sun, Y.Q.; Flint, A.; Butcher, J.; Naikare, H.; Stintzi, A. Characterization of the oxidative stress stimulon and PerR regulon of Campylobacter jejuni. BMC Genom. 2009, 10, 481. [CrossRef]

41. Stintzi, A.; Marlow, D.; Palyada, K.; Naikare, H.; Panciera, R.; Whitworth, L.; Clarke, C. Use of genome-wide expression profiling and mutagenesis to study the intestinal lifestyle of Campylobacter jejuni. Infect. Immun. 2005, 73, 1797-1810. [CrossRef]

42. Kendall, J.J.; Barrero-Tobon, A.M.; Hendrixson, D.R.; Kelly, D.J. Hemerythrins in the microaerophilic bacterium Campylobacter jejuni help protect key iron-sulphur cluster enzymes from oxidative damage. Environ. Microbiol. 2014, 16, 1105-1121. [CrossRef]

43. Mavri, A.; Abramovič, H.; Polak, T.; Bertoncelj, J.; Jamnik, P.; Smole Možina, S.; Jeršek, B. Chemical properties and antioxidant and antimicrobial activities of Slovenian propolis. Chem. Biodivers. 2012, 9, 1545-1558. [CrossRef]

44. Tsai, Y.-C.; Wang, Y.-H.; Liou, C.-C.; Lin, Y.-C.; Huang, H.; Liu, Y.-C. Induction of oxidative DNA damage by flavonoids of propolis: its mechanism and implication about antioxidant capacity. Chem. Res. Toxicol. 2012, 13, 191-196. [CrossRef] [PubMed]

45. Hofreuter, D. Defining the metabolic requirements for the growth and colonization capacity of Campylobacter jejuni. Front. Cell. Infect. Microbiol. 2014, 4. [CrossRef] [PubMed]

46. Carrillo, C.D.; Taboada, E.; Nash, J.H.E.; Lanthier, P.; Kelly, J.; Lau, P.C.; Verhulp, R.; Mykytczuk, O.; Jonathan, S.; Findlay, W.A.; et al. Genome-wide expression analyses of Campylobacter jejuni NCTC11168 reveals coordinate regulation of motility and virulence by flhA. J. Biol. Chem. 2004, 279, 20327-20338. [CrossRef] [PubMed]

47. Gaynor, E.C.; Cawthraw, S.; Manning, G.; MacKichan, J.K.; Falkow, S.; Newell, D.G. The genome-sequenced variant of Campylobacter jejuni NCTC 11168 and the original clonal clinical isolate differ markedly in colonization, gene expression, and virulence-associated phenotypes. J. Bacteriol. 2004, 186, 503-517. [CrossRef]

48. Gaynor, E.C.; Wells, D.H.; MacKichan, J.K.; Falkow, S. The Campylobacter jejuni stringent response controls specific stress survival and virulence-associated phenotypes. Mol. Microbiol. 2005, 56, 8-27. [CrossRef]

49. Guerry, P.; Poly, F.; Riddle, M.; Maue, A.C.; Chen, Y.H.; Monteiro, M.A. Campylobacter polysaccharide capsules: virulence and vaccines. Front. Cell Infect. Microbiol. 2012, 15, 2-7. [CrossRef]

50. Stintzi, C.M.; King, M.; Haardt, M.; Armstrong, G.D. Campylobacter jejuni motility and invasion of Caco-2 cells. Infect. Immun. 1995, 63, 4295-4300. [PubMed]

51. Le, M.T.; Porcelli, I.; Weight, C.M.; Gaskin, D.J.H.; Carding, S.R.; van Vliet, A.H.M. Acid-shock of Campylobacter jejuni induces flagellar gene expression and host cell invasion. Eur. J. Microbiol. Immunol. 2012, 2, 12-19. [CrossRef]

52. Kalmokoff, M.; Lanthier, P.; Tremblay, T.L.; Foss, M.; Lau, P.C.; Sanders, G.; Austin, J.; Kelly, J.; Szymanski, C.M. Proteomic analysis of Campylobacter jejuni 11168 biofilms reveals a role for the motility complex in biofilm formation. J. Bacteriol. 2006, 188, 4312-4320. [CrossRef]

53. Konkel, M.E.; Kim, B.J.; Klena, J.D.; Young, C.R.; Ziprin, R. Characterization of the thermal stress response of Campylobacter jejuni. Infect. Immun. 1998, 66, 3666-3672.

(C) 2019 by the authors. Licensee MDPI, Basel, Switzerland. This article is an open access article distributed under the terms and conditions of the Creative Commons Attribution (CC BY) license (http://creativecommons.org/licenses/by/4.0/). 